\title{
Intracavitary and Extracavitary lliac Extended Fixation Using Porous Metal Augments for Paprosky Type 3 Acetabular Defects in Revision Total Hip Arthroplasty: A Minimum 2 Years Follow-up
}

Hao Tang

Beijing Jishuitan Hospital

Yixin Zhou ( $\sim$ orthoyixin006@163.com )

Beijing Jishuitan Hospital

Zhuyi Ma

Beijing Jishuitan Hospital

Yong Huang

Beijing Jishuitan Hospital

Shengjie Guo

Beijing Jishuitan Hospital

Research article

Keywords: revision total hip arthroplasty, severe bone defect, porous metal augment, intracavitary iliac extended fixation, extracavitary iliac extended fixation

Posted Date: December 1st, 2019

DOl: https://doi.org/10.21203/rs.2.17840/v1

License: (c) (i) This work is licensed under a Creative Commons Attribution 4.0 International License. Read Full License 


\section{Abstract}

Background: We proposed a new concept of "iliac extended fixation" in revision total hip arthroplasty (THA) as fixation extending superiorly $2 \mathrm{~cm}$ beyond the original acetabular rim with porous metal augments, which was further classified into intracavitary and extracavitary fixation. This study reports the minimum 2 years outcome of the iliac extended fixation technique in patients with Paprosky type 3 acetabular defects.

Methods: Thirty two revision THA patients were retrospectively reviewed who underwent reconstruction with the concept of iliac extended fixation from 2014 to 2016 in our hospital. Patients were assessed using the Harris Hip Score (HHS) and the Western Ontario and McMaster Universities Osteoarthritis Index score (WOMAC). In addition, radiographs were assessed and patient reported satisfaction was collected.

Results: At an average follow-up of 40 months (range 25 - 64 months), the postoperative HHS and WOMAC scores were significantly improved at the last follow-up $(p<0.001)$. The postoperative horizontal and vertical locations of the COR were significantly improved from the preoperative measurements $(p<0.05)$. Two $(6.3 \%)$ patients were dissatisfied with the outcome. The extracavitary iliac extended fixation group had significantly more horizontal screws fixation $\left(4.6 \pm 25.7^{\circ}\right.$ vs $\left.41.9 \pm 37.8^{\circ}, p<0.001\right)$ and higher rate of osteointegration in zone $1 \mathrm{~A}(91.7 \%$ vs $50.0 \%$, $\mathrm{p}=0.023)$ than the intracavitary iliac extended fixation group.

Conclusions: Intracavitary and extracavitary iliac extended fixation with porous metal augments and cementless cups are effective in reconstructing severe superior acetabular bone defects, with promising short-term clinical and radiographic outcome.

\section{Introduction}

The quality of the superior acetabular bone stock is critical to prosthetic acetabular component fixation and load transmission [29]. Unfortunately, superior acetabular bone defects are commonly encountered in revision total hip arthroplasty (THA) [14, 16, 26, 34]. Paprosky type 3 defects indicate severe and extensive superior acetabular bone loss, often requiring reconstruction to be extended to an area at least $2 \mathrm{~cm}$ above the original acetabular rim[26]. Several different methods exist as a means of reconstructing superior bone defects, including jumbo cups, structural allografts, cup-cage construction, and impaction bone graft with cemented cups [14, 34]. Each method has been successful in selected cases. However, these traditional methods frequently encountered relatively lower survivorship due to mechanical failures, or compromised hip biomechanics as a result of highly riding hip centers resulting from obtaining adequate bony coverage of cup, particularly in patients with severe superior acetabular bone defects $[5,25]$.

The introduction of porous metal augments has provided a promising solution to this problem $[3,8,13,32]$, and have been used in the reconstruction of Paprosky type 3 severe superior acetabular bone defects. Jenkins et al. classified the use of metal augments in the superior aspect of the acetabulum into the three types, namely "flying buttress", "dome" and "footing" [15]. This classification is according to the augment's location and orientation, and is instructive to the intraoperative application of porous metal augments. However, it does not cover all types of intraoperative applications of porous metal augments, especially those extending beyond the inferior pole of the sacroiliac joint, like buttress augments and stacked slope augments, which have the potential to feature distinct technical and biomechanical characteristics. There is a paucity of literature reporting the intraoperative classifications and rationale for reconstruction using porous metal augments.

In the current study, we propose the concept of "iliac extended fixation", as compared to the jumbo cup technique and juxta acetabular fixation, which are commonly used in patients with Paprosky type II defects. Iliac extended fixation is 
defined as acetabular reconstruction components that are fixed to the iliac bone at a level $2 \mathrm{~cm}$ higher than the original superior edge of the acetabulum. The rational for the $2 \mathrm{~cm}$ cutoff is based on two aspects: on one hand, our clinical observation that in most patients, the bone structure turns to the ala of ilium, where bone stock is dramatically decreased compared with that of the juxta-acetabular area within $2 \mathrm{~cm}$ of the original acetabular rim[1]; and on the other hand the biomechanical disadvantages of increased joint reaction force, risk of loosening, and decreased range of motion by migrating center of rotation superiorly over $2 \mathrm{~cm}[4,17,18,21,24,35,37]$.

Utilizing cementless porous metal augments, iliac extended fixation is further classified into intracavitary and extracavitary fixation types, which encompass different local mechanical conditions of compressive and shear stresses, respectively. Intracavitary iliac extended fixation (IIEF) was defined as cavitary bone loss exceeding $2 \mathrm{~cm}$ superior to the original acetabular rim, and a single slope augment or stacked augments with $\geq 2 \mathrm{~cm}$ thickness that could be contained in the bone bed and stabilized by compressive stress with minimal shear stress. Extracavitary iliac extended fixation (EIEF) was defined as the segmental superior bone loss so extensive that augments could not be contained in the bone bed. Thus, achievement of primary stability in EIEF required directly fixing an augment to the iliac wing using multiple buttress screws to resist shear stress. Both IIEF and EIEF sought to provide stable superior points of fixation with a well-positioned cementless hemispherical cup.

This new concept may help establish intraoperative mechanical principles to guide the reconstruction of severe superior acetabular bone defects. With the IIEF and EIEF techniques, load is transmitted to the superior area distant from the original acetabular rim, with the shear and compressive stresses taken into consideration in the choice and application of porous metal augments during revision THA. In the current study, we asked two major questions: $\mathbb{\nabla}$ What are the minimum 2 years postoperative clinical and radiological results of iliac extended fixation technique in patients with Paprosky type 3 superior acetabular defects? $\otimes$ Are there any preoperative, intraoperative, and postoperative differences between the two groups of IIEF and EIEF techniques?

\section{Materials And Methods}

\section{Patients}

This study was approved by the hospital ethics committee. In order to enroll patients reconstructed with the concept of iliac extended fixation, 102 consecutive patients who underwent revision THA with the use of porous metal augments at our institution from January 2014 to October 2016 were retrospectively reviewed. The inclusion criteria consisted of patients undergoing revision THA, acetabular reconstruction with a cementless hemispherical cup and porous metal augments, construction extending superiorly to more than $2 \mathrm{~cm}$ above the original upper acetabular rim, and minimal follow-up of 24 months. Of the initial 99 patients that were reviewed, 32 patients were deemed eligible based on the inclusion criteria and were therefore enrolled in this study. The other 72 patients were excluded because the augments did not extend over $2 \mathrm{~cm}$ above the original acetabular rim.

Trabecular metal augments made from tantalum (TM Augment; Zimmer, Warsaw, IN) or titanium (Restoration wedge augment; Stryker, Mahwah, NJ) were utilized to reconstruct the superior acetabular defects. There were twelve patients reconstructed with the EIEF technique, using a single buttress augment or combined with other augments, or a flying buttress using slope augments [15] (Table 1); twenty patients reconstructed with the IIEF technique, fourteen of whom using a single superior slope augment, and the other six with stacked superior slope augments (Table 2). Three patients received a combined application of augments from the two manufacturers, according to the concrete morphology of bone defects and suitable metal augments, and other patients received augments from a single manufacturer. Multiple holed revision cementless hemispherical cups (TM; Zimmer, Warsaw, IN) were inserted after 
insertion of augments with average diameter of 56 (range 44-68) mm. Averagely 6.2(range 2-10) screws were used for each patient, among which 3 (range 1-5) screws for the cup, and 3.3 (2-7) screws for augments. Thirteen (40.6\%) patients received inferior screws into the ischial or ilium ramus. Eight (25.0\%) patients received augments in the inferior anterior/posterior aspect. No autograft or allograft of bone was used in all patients.

Patients also underwent revision of the femoral component, including 17(53.1\%) with a modular revision femoral stem (RM; Stryker, Mahwah, NJ), 7(21.9\%) with a monoblock femoral stem (Wagnar; Zimmer, Warsaw, IN), and the other 5(15.6\%) patients with only femoral head revision with a ceramic head lined by a titanium sleeve (TS; DePuy, Warsaw, IN).

The average patient age at the time of surgery was 57 years (range 38-78 years), the average body mass index (BMI) was 25.0 (range 18.7-33.7), and $13(40.6 \%$ ) patients were female. On average, patients had 1.6 (range 1-5) previous hip operations. There were 21 patients (65.6\%) revised for aseptic loosening, 6 (18.8\%) for periprosthetic infection, 3 for recurrent dislocation (9.4\%), 1(3.1\%) for severe acetabular side osteolysis without component loosening, and 1 (3.1\%) for periprosthetic fracture. The preoperative Charlson comorbidity score was 0 in 26 (81.3\%) patients, 1 in 4 (12.5\%) patients, and 2 in 2 patients (6.3\%). The average duration from first THA to surgery was 14 (range 0.5-31) years. The average number of previous surgeries for the index hip was 1.6 (range 1-5).

\section{Surgical Technique}

All the patients were cleared of infection at the time of index revision surgery. Patients revised for infection were treated with staged revision and sensitive antibiotics for 6 weeks, and the final revisions were not commenced until joint aspirations as well as ESR and CRP turned normal. Same protocol was followed for the patient with acute infection after revision. A posterior lateral approach was employed in all hips. The femoral head was removed after dislocation of the hip, and the femoral stem was removed if it was deemed loose or considered necessary for exposure, reconstruction, or if evidence of trunionosis was visible. The femoral stems in 7 (21.9\%) hips were preserved with only the acetabular side revised. Extended trochanteric osteotomy was done in 6 (18.8\%) hips because of difficulty in removing the femoral components.

The acetabular cups were then removed, and intraoperative tissues were sent to culture and pathology for detection of any possible residual infection. Fibrous tissue was then removed to fully expose the acetabulum and the bone defects. Patients with pelvic discontinuity were then treated with distraction technique by inserting a $3 \mathrm{~mm}$ pin into the ilium and ischium ramus, respectively, and then distracting the cranial and caudal fragments with a pliers holding the two pins, in order to stabilize the anterior and posterior column before preparation of augment and cup bony bed $[7,31]$.

The site, size, and shape of the bone defects were determined before reaming and preparing for insertion of the augment and metal shell. A hemispherical cup trial or reamer was positioned to a target level by aiming at the optimal COR and contact area of the bone bed. Augment trials were then used to determine the shape, size and position of the final metal augment.

Buttress and slope augments were implanted first and fixated with screws to the host bone, followed by a multiple holed, trabecular metal shell that was impacted and press fit to ensure primary stability of the whole cementless construct. For a slope augment, a tantalum augment (TM Augment; Zimmer, Warsaw, IN) was the first choice for use; if the available bone bed required more versatile screw fixation, a titanium augment (Restoration Wedge Augment; Stryker, Mahwah, NJ) was considered (Figs. 1 and 2). Cement was placed between the augments and the augmentcup interface to unify these metal components into one solid unit. Multiple screws were then inserted through the 
porous metal shell. Polyethylene liners with a $10^{\circ}$ high wall were used in 14 (43.8\%) patients, and neutral polyethylene liners in the other half of patients. A $28 \mathrm{~mm}$ diameter Co-Cr-Mo alloy head was used in 2 (6.3\%) patients, and $32 \mathrm{~mm}$, $36 \mathrm{~mm}$ and $40 \mathrm{~mm}$ diameter ceramic heads in 18 (56.3\%), 11 (34.4\%) and 1 (3.1\%) patients, respectively. There were no significant differences in the preoperative demographic factors between the EIEF and IIEF groups (Table. 4). The EIEF group had significantly higher preoperative vertical location of COR, and more screws used for augment fixation than the IIEF group (Table. 4).

Postoperatively, patients with IIEF were generally allowed to ambulate with touch-down weight bearing for the first 4 weeks, then encouraged to walk with partial weight bearing for another 8 weeks, which could be accelerated according to the intraoperative evaluation of reconstruct stability by the senior author (YXZ). Patients with EIEF were allowed to start touch-down weight bearing 2 weeks after surgery and for 6 weeks, and then partial weight bearing for another 4 weeks. By the 12th week, all patients were urged to walk with full weight bearing. Antibiotic prophylaxis with 2 grams of cefuroxime every 12 hours was initiated and then discontinued 48 hours post-operatively for aseptic cases. Antibiotics sensitive to the specific bacteria were used for second stage revision of infection cases according to previous antimicrobial susceptibility testing. Subcutaneous heparin and intermittent elastic compression were used as routine measures to prevent thromboembolic complications in the hospital, which was transitioned to low dose aspirin (100 mg per day) for 5 weeks after discharge.

\section{Clinical Data}

Patients were asked to revisit the hospital at 3 months, 6 months, 1 year, and then yearly after surgery. The Harris Hip Score (HHS) and the Western Ontario and McMaster Universities Osteoarthritis Index (WOMAC, range 0-96 with higher score indicating worse outcome) were used for clinical evaluation. Clinical failure was defined as loosening or any complications requiring surgical removal of the cup. Patients also reported satisfaction based on an five-level subjective scale (very satisfied, satisfied, neutral, dissatisfied, or very dissatisfied), which was collected at the last follow-up[6].

\section{Radiological Evaluation}

Anteroposterior, lateral and Judet view radiographs of the bilateral hips were taken for all patients 1 week prior to the planned operation. Two surgeons $(\mathrm{YH}, \mathrm{HT})$ assessed the severity of the acetabular bone deficiency according to the preoperative radiographs on the basis of the Paprosky acetabular bone defect classification [27, 33]. Any discrepancies between the two surgeons were re-examined by the senior consultant surgeon (YXZ). There were 13 (40.6\%) patients classified as Paprosky type 3A, 19 (59.4\%) as type 3B. Five (15.6\%) of the type 3B patients were assessed to have pelvic discontinuity.

Anteroposterior and lateral radiographs of the bilateral hips were taken for all patients immediately after the operation, as well as at 3,6 , and 12 months, and then annually thereafter, which is according to standard protocol at our hospital. Magnification was corrected by referring to the already known diameter of the femoral head. The height and the horizontal location of the center of rotation (COR) were determined by measuring the distance from COR to the inter-teardrop line and a vertical line passing the ipsilateral teardrop, respectively $[2,15]$. Deviation of reconstructed COR was measured as the distance between postoperative COR and the anatomic COR mirrored from the normal contralateral hip to the revised side. In scenarios of abnormal contralateral hip, Ranawat triangle method was utilized instead to determine the anatomic COR, by calculating the acetabular height as $20 \%$ of pelvis height[28].

The radiographic abduction angle was assessed by calculating the angle between the inter-teardrop line and a line passing the longest axis of the cup's projected ellipse rim. The radiographic anteversion angle was defined as the arcsin (short axis/long axis), as defined by Lewinnek et al [20]. 
The area surrounding the cup was divided into the 3 zones using the modified Delee-Charnley method, and zone 1 around the superior augments was further divided into two sub-zones $1 \mathrm{~A}$ and $1 \mathrm{~B}$, with $1 \mathrm{~A}$ in the superior lateral half and $1 \mathrm{~B}$ in the inferior medial half of the bone-augment interface (Fig. 1-3). Radiolucent lines and osteointegration around the cup and augment were assessed to determine the stability of fixation of the acetabular components[36]. The acetabular cup was diagnosed as unstable if there was evidence of a continuous radiolucent line $\geq 1 \mathrm{~mm}$ wide around all the three acetabular zones, or if any progressive prosthesis displacement could be detected during followup. Fibrous stable was defined as evidence of a radiolucent line $\otimes 1 \mathrm{~mm}$ wide around two of the three acetabular zones, while bone ingrowth stability was defined as intimate contact between the bone bed and metal surfaces, but no radiolucent lines in two or three of all of the acetabular zones $[10,36]$. The orientation of screws anchoring the augments were measured in reference to the inter-teardrop line, with screws pointing cephalad defined as positive values, and screws pointing caudally defined as negative values (Fig. 2B).

\section{Statistical Analysis}

The horizontal and vertical COR location data were compared between the preoperative and postoperative measurements and also between the studied and the contralateral hips using the student $t$ test. All statistical analyses were performed using the SPSS statistical software package (version 15.0; IBM, Armonk, NY, USA), and the level of significance was set at $\mathrm{P}<.05$ for a single comparison.

\section{Results}

This cohort of patients was followed for an average of 40 months (range 25-64 months) after surgery. All patients were able to ambulate freely at last follow up. The average HHS score and WOMAC improved from 20.1 (range 6 .032.0) and 50.3 (range 10.0-85.0) preoperatively, to 81.0 (range 45.0-97.0) and 16.0 (range 4.0-41.0) postoperatively, respectively ( $p \otimes 0.001$, Table. 3 ). All components were found to be stable, with evidence of stable bone ingrowth identified for all patients based on the radiographic evaluation. There were 21 (65.6\%) patients very satisfied with the outcome, $6(18.8 \%)$ satisfied with the outcome, $2(6.3 \%)$ patients dissatisfied with the outcome. One patient was dissatisfied because of little improvement in hip function, and the other patient with rheumatoid arthritis and bilateral total knee arthroplasties was dissatisfied due to lower limb weakness. One (3.1\%) patient was diagnosed as peri-prosthetic joint infection 6 months after the revision surgery, and subsequently underwent a twostaged revision. There were no clinical symptoms of infection and serial laboratory examinations of C-reactive protein and erythrocyte sedimentation rate were within normal range for 14 months after the last revision surgery, and the patient rated "satisfied" with the current outcome.

The average postoperative abduction and anteversion angles of the acetabular cup were $39.7^{\circ}\left(\right.$ range $\left.28.4^{\circ}-58.5^{\circ}\right)$ and $12.5^{\circ}$ (range $2.0^{\circ}-23.8^{\circ}$ ), respectively. The average postoperative horizontal and vertical locations of the COR from the inter-teardrop line were $31.5 \mathrm{~mm}$ (range 15.1-45.7 mm) and $23.1 \mathrm{~mm}$ (range 1.7-42.7 mm), respectively, and the average deviation of COR from anatomic COR was $5.2 \pm 7.2 \mathrm{~mm}$ horizontally and $-1.0 \pm 9.3 \mathrm{~mm}$ vertically, all of which were significantly different from preoperative results ( $\mathrm{p} \otimes 0.05$; Table 3 ). There were 12 patients (37.5\%) with regional radiolucent lines at the zone $1 \mathrm{~A}$ augment region, and 1 (3.1\%) patient found with regional radiolucent lines < $1 \mathrm{~mm}$ wide in modified Delee-Charnley zone 2 of the acetabular cup, which was formed between the extruded cement and the corresponding radiopaque line of sclerotic bone. There were no radiolucent lines found at the zone 1B, zone 3 , and the interface between cups and metal augments. All patients had sites of osteointegration between augments and bone, and between cups and host bone, identified on follow-up radiographies.

Between the EIEF and IIEF group, there was no significant difference in HSS scores, WOMAC scores, and satisfaction rate. For radiological results, there was no significant difference between the two groups in the horizontal and vertical 
location of COR, and orientation of cups (Table. 5). The EIEF group had significantly higher rate of osteointegration in zone $1 \mathrm{~A}$ than the IIEF group ( $91.7 \%$ vs $50.0 \%, p=0.023$, Table. 5$)$. The angle formed between the intersection of screws and inter-teardrop line was significantly smaller in the EIEF group than the IIEF group $\left(4.6 \pm 25.7^{\circ}\right.$ vs $41.9 \pm$ $37.8^{\circ}, \mathrm{p}<0.001$, Table. 5).

\section{Discussion}

This study revealed that iliac extended fixation successfully reconstructed the hip COR, and achieved satisfactory clinical and radiographic outcomes for patients with severe superior acetabular bone defects in revision THA. There were no statistical differences in the major clinical and radiological results between the IIEF and EIEF technique groups, despite the latter group had more severe proximal migration of COR in preoperative radiographies. We did found statistical difference in the orientation of screws fixing the augments between IIEF and EIEF groups, which had potential biomechanical implications.

In this study, the concept of "iliac extended fixation" is proposed to differentiate it from junta-acetabular fixation, which is close to the original acetabulum. According to the Paprosky classification system, the superior aspect of the acetabulum comprises an important part of the bone defect pattern. Biomechanical studies have revealed that the superior bone serves as the major support structure for acetabular cups and an essential component in the process of transmitting load from the hip to the sacroiliac joint $[12,19,23]$, and superior and lateral migration of the COR significantly increases joint reaction force, risk of loosening, and decreased range of motion $[4,17,18,21,24,35,37]$. In knee revision procedures, Haddad et al. proposed the concept of zone fixation in the metaphysis and diaphysis, while preserving the knee joint line level $[12,22]$. Similarly, in our practice of iliac extended fixation technique, viable bone is pursued within the whole semi-pelvis to achieve good primary stability and further biological fixation.

Iliac extended fixation is defined as extending beyond $2 \mathrm{~cm}$ superior to the anatomic acetabular rim, based on anatomical and biomechanical rational[ $1,4,17,18,21,24,35,37]$. Augments used at juxta-acetabular region can be considered a rim restoration procedure, while in iliac extended fixation, a superior or superior posterior/anterior supporting point is created by extending porous metal across the worst quality and quantity of bone potentially remote to acetabular rim. In comparison with juxta-acetabular fixation, iliac extended fixation requires more surgical exposure and is more difficult to obtain adequate primary mechanical stability. Our data revealed that bone ingrowth fixation was identified between the bone-cup and bone-augment interface in all patients, indicating that with iliac extended fixation achieved sufficient initial stability and subsequent biologic osteointegration without compromising COR and cup orientation (Table 3-5).

The iliac extended fixation technique is aimed to reconstruct severe cranial acetabular defects while reconstructing the COR and cup orientation as optimal as we can. In the present study, the postoperative COR were significantly lower compared to the preoperative COR, more close to the anatomic COR (Table 3). The hip biomechanics were therefore improved, which is consistent with previous reports [15]. Restoration of the COR helps decrease leg length discrepancy and avoid increasing the lever arm, which acts on the head/neck taper caused by increased neck length [11]. Moreover, superior placement of the shell may increase the joint reaction force, in addition to the risk of impingement, loosening and hip instability [9].

The iliac extended fixation technique can be further classified into two groups of EIEF and IIEF. In this cohort, IIEF contained a single superior slope augment or stacked slope augments mounted into the cavitary bone defects, usually below the level of sacroiliac joint. As the EIEF featured no cavitary bone to prevent the augments from migrating proximally, buttress augments were utilized to extend the construct to the level of sacroiliac joint. There 
were several studies reporting the use of porous metal augments in revision THA with promising short term outcomes $[3,8,13,32]$. Despite this, very few studies have reported the classifications of augment reconstructions in the superior acetabular area. Derek et al reported 5-12 year follow-up of 85 revision THA cases with porous metal augments and classified the use of slope augments in the superior aspect into the three types, namely "flying buttress", "dome" and "footing"[15]. This classification is not contradictory to the concept of iliac extended fixation, as the essence of extended fixation is the bridging of bone defects via augments to establish a supportive superior point; any augment configuration can be used as long as mechanical stability and anatomical COR are achieved. To the best of our knowledge, the dome and footing techniques could fall into the IIEF group, and the flying buttress technique could be the subtype of EIEF if it meets the definition of being more than $2 \mathrm{~cm}$ superior to the anatomic acetabular rim.

Our data showed that the EIEF group had similar postoperative vertical and horizontal location of COR compared with the IIEF group, in spite of the higher COR in preoperative radiographies. Spanyer et al previously reported using a buttress augment for successful repairing the anterior column through the direct anterior approach [30], while Ballester et al reported the application of buttress augments in treatment of severe acetabular bone loss [2]. The restoration of COR using EIEF technique is similar to those of buttress augment reported in the literature.

There are several biomechanical, surgical and postoperative rehabilitation implications of this sub-classification. Our data revealed that the screw orientation was significantly more horizontal in the EIEF group than the IIEF group when measured in reference of the inter-teardrop line $\left(4.6^{\circ}\right.$ vs. $\left.41.9^{\circ}\right)$. This difference in screw orientation is most likely a result of different biomechanics of the two groups. The EIEF features high shear force in the augment-bone interface, since no bony wall is available to resist the joint reaction force. This then surgically requires horizontal buttress screws to achieve stable fixation of metal augments with high friction coefficient to counteract the shear stress, and adequate intraoperative exposure of the superior aspect of acetabulum usually to the level of sacroiliac joint. Differently, superior migration of metal augments is prevented by bony walls in IIEF, which then features mainly compressive forces at the augment-bone interface. Surgically, IIEF requires oblique screws perpendicular to the metalbone interface to counteract the tangential shear force while allowing potential dynamic compression along the screws. In our practice, rehabilitation for patients with EIEF was generally more conservative compared with that for patients with IIEF, who could be allowed with earlier weight bearing according to the intraoperative evaluation of the reconstruct stability.

The EIEF group had higher rate of osteointegration in zone $1 \mathrm{~A}$ compared with the IIEF group (91.7\% vs $50.0 \%$, Table. 5). This might be caused by better bone-augment contact in zone $1 \mathrm{~A}$ of the EIEF group, and indicated that the EIEF technique successfully bridged the bony fixation of acetabular cup to the ilium. There is higher rate of radiolucent lines in zone $1 \mathrm{~A}$ in the IIEF group than in the EIEF group, although not statistically significant $(p=0.075$, Table. 5$)$ It is still unknown whether the radiolucent lines in zone 1A will cause possible loosening of the cementless construct, which necessitates longer term of follow up.

This study had several limitations. First, due to the short follow-up duration and small sample size, survivorship analysis and comparisons with other reconstruction methods were not conducted. The restoration of hip COR and good bone ingrowth in iliac extended fixation may contribute to improved hip function and long-term implant survivorship. Further study comparing the iliac extended fixation technique with other techniques should be compared. Second, the cement bond between the stacked metal components must be evaluated with long term follow up or in vitro fatigue tests to exclude micromotion and subsequent generation of abrasion. Third, it requires further biomechanical analyses to assess any potential differences in mechanical properties between juxta-articular 
within $2 \mathrm{~cm}$ of acetabulum and iliac extended reconstructions beyond $2 \mathrm{~cm}$ of acetabulum, as well as between EIEF and IIEF reconstructions.

The findings of this study indicate that EIEF and IIEF with porous metal augments and cementless cups are effective in reconstructing severe superior acetabular bone defects, with promising short-term clinical and radiographic outcome. The EIEF technique achieved satisfactory clinical and radiological outcomes similar to the IIEF technique in spite of higher preoperative COR, and required more horizontal intraoperative screw fixation for the augments.

\section{Declarations}

\section{Acknowledgements}

We would like to acknowledge the dedicated work of Mrs. Xueying Li for advices on statistics.

\section{Ethics approval and consent to participate}

The study was approved by the ethics committee of Beijing Jishuitan Hospital. Written consent to participate forms were obtained from patients.

\section{Consent for publication}

Written consent form for publication forms were obtained from patients.

\section{Funding}

This study was funded by the Beijing Municipal Science \& Technology Commission (Z181100001618005), the Beijing Municipal Human Resources and Social Security Bureau Funds for the Beijing Baiqianwan Talents Project 2016, the Beijing Talents Fund 2017, and Beijing Jishuitan Hospital Nova Program (XKXX201805).

\section{Availability of data and materials}

The datasets used and/or analysed during the current study are available from the corresponding author on reasonable request.

\section{Competing interests}

The authors declare that they have no competing interests.

\section{Authors' contributions}

$\mathrm{HT}$ analyzed and interpreted the patient data and drafted the manuscript. YXZ performed the surgeries and designed the study. ZYM and YH followed up the patients and did the radiographic measurement. SJG evaluated the radiographic results. All authors read and approved the final manuscript.

\section{Abbreviations}

HHS = Harris Hip Score; ROM = Range of Motion; WOMAC = Western Ontario and McMaster Universities Osteoarthritis Index; $\mathrm{COR}=$ Center of Rotation; IT line = Inter-Teardrop line; ETO = Extended Trochanteric Osteotomy 


\section{References}

1.

Antoniades J, Pellegrini VD Jr. Cross-sectional anatomy of the ilium: implications for acetabular component placement in total hip arthroplasty. Clin Orthop Relat Res. 2012;470:3537-41.

2.

Ballester Alfaro JJ, Sueiro Fernandez J. Trabecular Metal buttress augment and the Trabecular Metal cup-cage construct in revision hip arthroplasty for severe acetabular bone loss and pelvic discontinuity. Hip Int. 2010;20(Suppl 7):119-27.

3.

Banerjee S, Issa K, Kapadia BH, Pivec R, Khanuja HS, Mont MA. Systematic review on outcomes of acetabular revisions with highly-porous metals. International orthopaedics. 2014;38:689-702.

4.

Bicanic G, Delimar D, Delimar M, Pecina M. Influence of the acetabular cup position on hip load during arthroplasty in hip dysplasia. International orthopaedics. 2009;33:397-402.

5 .

Boscainos PJ, Kellett CF, Maury AC, Backstein D, Gross AE. Management of periacetabular bone loss in revision hip arthroplasty. Clin Orthop Relat Res. 2007;465:159-65.

6.

Bourne RB, Chesworth B, Davis A, Mahomed N, Charron K. Comparing patient outcomes after THA and TKA: is there a difference? Clin Orthop Relat Res. 2010;468:542-6.

7.

Brown NM, Hellman M, Haughom BH, Shah RP, Sporer SM, Paprosky WG. Acetabular distraction: an alternative approach to pelvic discontinuity in failed total hip replacement. Bone Joint J. 2014;96-B:73-7.

8.

Davies JH, Laflamme GY, Delisle J, Fernandes J. Trabecular metal used for major bone loss in acetabular hip revision. J Arthroplasty. 2011;26:1245-50.

9.

Dearborn JT, Harris WH. Acetabular revision arthroplasty using so-called jumbo cementless components: an average 7-year follow-up study. The Journal of arthroplasty. 2000;15:8-15.

10.

DeLee JG, Charnley J. Radiological demarcation of cemented sockets in total hip replacement. Clin Orthop Relat Res. 1976:20-32.

11.

Delp SL, Wixson RL, Komattu AV, Kocmond JH. How superior placement of the joint center in hip arthroplasty affects the abductor muscles. Clinical orthopaedics and related research. 1996:137-146.

12.

Graichen H, Scior W, Strauch M. Direct. Cementless, Metaphyseal Fixation in Knee Revision Arthroplasty With SleevesShort-Term Results. J Arthroplasty. 2015;30:2256-9.

13.

Grappiolo G, Loppini M, Longo UG, Traverso F, Mazziotta G, Denaro V. Trabecular Metal Augments for the Management of Paprosky Type III Defects Without Pelvic Discontinuity. J Arthroplasty. 2015;30:1024-9.

14.

Jain S, Grogan RJ, Giannoudis PV. Options for managing severe acetabular bone loss in revision hip arthroplasty. A systematic review. Hip Int. 2014;24:109-22.

Page $10 / 18$ 
15.

Jenkins DR, Odland AN, Sierra RJ, Hanssen AD, Lewallen DG. Minimum Five-Year Outcomes with Porous Tantalum Acetabular Cup and Augment Construct in Complex Revision Total Hip Arthroplasty. J Bone Joint Surg Am. 2017;99:e49.

16.

Johanson NA, Driftmier KR, Cerynik DL, Stehman CC. Grading acetabular defects: the need for a universal and valid system. J Arthroplasty. 2010;25:425-31.

17.

Johnston RC, Brand RA, Crowninshield RD. Reconstruction of the hip. A mathematical approach to determine optimum geometric relationships. J Bone Joint Surg Am. 1979;61:639-52.

18.

Komiyama K, Nakashima Y, Hirata M, Hara D, Kohno Y, Iwamoto Y. Does High Hip Center Decrease Range of Motion in Total Hip Arthroplasty? A Computer Simulation Study. The Journal of Arthroplasty. 2016;31:2342-7.

19.

Levine DL, Dharia MA, Siggelkow E, Crowninshield RD, Degroff DA, Wentz DH. Repair of periprosthetic pelvis defects with porous metal implants: a finite element study. J Biomech Eng. 2010;132:021006.

20.

Lewinnek GE, Lewis JL, Tarr R, Compere CL, Zimmerman JR. Dislocations after total hip-replacement arthroplasties. J Bone Joint Surg Am. 1978;60:217-20.

21.

Morag G, Zalzal P, Liberman B, Safir O, Flint M, Gross AE. Outcome of revision hip arthroplasty in patients with a previous total hip replacement for developmental dysplasia of the hip. J Bone Joint Surg Br. 2005;87:1068-72. 22.

Morgan-Jones R, Oussedik SI, Graichen H, Haddad FS. Zonal fixation in revision total knee arthroplasty. Bone Joint J. 2015;97-B:147-9.

23.

Munro JT, Fernandez JW, Millar JS, Walker CG, Howie DW, Shim VB. Altered load transfer in the pelvis in the presence of periprosthetic osteolysis. J Biomech Eng. 2014;136.

24.

Pagnano W, Hanssen AD, Lewallen DG, Shaughnessy WJ. The effect of superior placement of the acetabular component on the rate of loosening after total hip arthroplasty. J Bone Joint Surg Am. 1996;78:1004-14.

25.

Paprosky W, Sporer S, O'Rourke MR. The treatment of pelvic discontinuity with acetabular cages. Clin Orthop Relat Res. 2006;453:183-7.

26.

Paprosky WG, Perona PG, Lawrence JM. Acetabular defect classification and surgical reconstruction in revision arthroplasty. A 6-year follow-up evaluation. J Arthroplasty. 1994;9:33-44.

27.

Paprosky WG, Perona PG, Lawrence JM. Acetabular defect classification and surgical reconstruction in revision arthroplasty. A 6-year follow-up evaluation. Journal of Arthroplasty. 1994;9:33-44.

28.

Ranawat CS, Dorr LD, Inglis AE. Total hip arthroplasty in protrusio acetabuli of rheumatoid arthritis. J Bone Joint Surg Am. 1980;62:1059-65.

29. 
Schuller HM, Dalstra M, Huiskes R, Marti RK. Total hip reconstruction in acetabular dysplasia. A finite element study. J Bone Joint Surg Br. 1993;75:468-74.

30.

Spanyer JM, Beaumont CM, Yerasimides JG. The Extended Direct Anterior Approach for Column Augmentation in the Deficient Pelvis: A Novel Surgical Technique, and Case Series Report. J Arthroplasty. 2017;32:515-9.

31.

Sporer SM, Bottros JJ, Hulst JB, Kancherla VK, Moric M, Paprosky WG. Acetabular distraction: an alternative for severe defects with chronic pelvic discontinuity? Clin Orthop Relat Res. 2012;470:3156-63.

32.

Sporer SM, Paprosky WG. The use of a trabecular metal acetabular component and trabecular metal augment for severe acetabular defects. J Arthroplasty. 2006;21:83-6.

33.

Sporer SM, Paprosky WG, O'Rourke MR. Managing bone loss in acetabular revision. Instr Course Lect. 2005;55:28797.

34.

Sporer SM, Paprosky WG, O'Rourke MR. Managing bone loss in acetabular revision. Instr Course Lect. 2006;55:28797.

35.

Watts CD, Martin JR, Fehring KA, Griffin WL. Inferomedial Hip Center Decreases Failure Rates in Cementless Total Hip Arthroplasty for Crowe II and III Hip Dysplasia. J Arthroplasty. 2018;33:2177-81.

36.

Weeden SH, Schmidt RH. The use of tantalum porous metal implants for Paprosky 3A and 3B defects. J Arthroplasty. 2007;22:151-5.

37.

Yoder SA, Brand RA, Pedersen DR, O'Gorman TW. Total hip acetabular component position affects component loosening rates. Clin Orthop Relat Res. 1988:79-87.

\section{Tables}


Table. 1 Data of 12 patients treated with extracavitary extended fixation by a single buttress augment or combined with superior slope augments

\begin{tabular}{|c|c|c|c|c|c|c|c|c|}
\hline No. & $\begin{array}{l}\text { Sex/ } \\
\text { Age } \\
\text { (years) }\end{array}$ & Side & $\begin{array}{l}\text { Indication } \\
\text { to revision }\end{array}$ & $\begin{array}{c}\text { Paprosky } \\
\text { classification }\end{array}$ & $\begin{array}{l}\text { Abduction/Anteversion } \\
\left({ }^{\circ}\right)\end{array}$ & $\begin{array}{l}\text { Vertical COR } \\
\text { Preop./Postop. } \\
\text { (mm) }\end{array}$ & $\begin{array}{c}\text { Horizontal } \\
\text { COR } \\
\begin{array}{c}\text { Preop./Postop. } \\
\text { (mm) }\end{array} \\
\end{array}$ & comments \\
\hline \multicolumn{9}{|c|}{ Single superior buttress augment } \\
\hline 1 & $\mathrm{M} / 60$ & $\mathrm{~L}$ & $\mathrm{AL}$ & IIIA & $31 / 10$ & $52 / 8$ & $30 / 38$ & \\
\hline 2 & $\mathrm{~F} / 41$ & $\mathrm{R}$ & $\mathrm{AL}$ & IIIA & $39 / 13$ & $80 / 2$ & $46 / 15$ & \\
\hline 3 & $\mathrm{M} / 58$ & $\mathrm{~L}$ & $\mathrm{AL}$ & IIIB & $44 / 11$ & $28 / 27$ & $35 / 30$ & \\
\hline \multicolumn{9}{|c|}{ Buttress augment combined with a shim augment } \\
\hline 4 & $\mathrm{M} / 66$ & $\mathrm{R}$ & PPF & IIIB & $34 / 14$ & $31 / 25$ & $31 / 28$ & $\begin{array}{l}\text { Stem not } \\
\text { revised }\end{array}$ \\
\hline 5 & $\mathrm{~F} / 68$ & $\mathrm{~L}$ & PJI & IIIB & $43 / 15$ & $60 / 21$ & $74 / 30$ & \\
\hline 6 & $\mathrm{~F} / 63$ & $\mathrm{R}$ & $\mathrm{AL}$ & IIIA & $36 / 10$ & $61 / 18$ & $55 / 24$ & \\
\hline 7 & $\mathrm{~F} / 65$ & $\mathrm{~L}$ & $\mathrm{AL}$ & IIIB & $35 / 24$ & $27 / 23$ & $34 / 34$ & $\mathrm{PD}$ \\
\hline \multicolumn{9}{|c|}{ Buttress augment combined with superior slope augments } \\
\hline 8 & $\mathrm{M} / 57$ & $\mathrm{R}$ & $\mathrm{AL}$ & IIIB & $33 / 5$ & $24 / 14$ & $34 / 32$ & $\mathrm{PD}$ \\
\hline 9 & $\mathrm{~F} / 71$ & $\mathrm{~L}$ & $\mathrm{AL}$ & IIIB & $43 / 13$ & $55 / 23$ & $55 / 36$ & $\mathrm{PD}$ \\
\hline 10 & $\mathrm{~F} / 55$ & $\mathrm{R}$ & $\mathrm{AL}$ & IIIB & $59 / 15$ & $57 / 43$ & $23 / 27$ & $\mathrm{PD}$ \\
\hline 11 & $\mathrm{~F} / 69$ & $\mathrm{R}$ & $\mathrm{AL}$ & IIIA & $43 / 14$ & $64 / 21$ & $42 / 35$ & $\begin{array}{l}\text { Stem not } \\
\text { revised }\end{array}$ \\
\hline \multicolumn{9}{|c|}{ Flying buttress using a slope augment } \\
\hline 12 & $\mathrm{M} / 44$ & $\mathrm{~L}$ & $\mathrm{AL}$ & IIIB & $41 / 14$ & $78 / 15$ & $47 / 25$ & \\
\hline
\end{tabular}

COR = Center of Rotation; HHS = Harris Hip Score; Preop. = Preoperatively; Postop. = Postoperatively; $\mathrm{AL}=$ aseptic loosening; $\mathrm{PPF}=$ Periprosthetic fracture; PJI = Periprosthetic Joint Infection; PD = Pelvic Discontinuity 
Table. 2 Data of 20 patients treated with intracavitary extended fixation by a single superior slope augment or stacked superior slope augments

\begin{tabular}{|c|c|c|c|c|c|c|c|c|}
\hline No. & $\begin{array}{c}\text { Sex/ } \\
\text { Age } \\
\text { (years) }\end{array}$ & Side & $\begin{array}{l}\text { Indication } \\
\text { to revision }\end{array}$ & $\begin{array}{c}\text { Paprosky } \\
\text { classification }\end{array}$ & $\begin{array}{l}\text { Abduction/Anteversion } \\
\left({ }^{\circ}\right)\end{array}$ & $\begin{array}{c}\text { Vertical COR } \\
\text { Preop./Postop. } \\
\text { (mm) }\end{array}$ & $\begin{array}{c}\text { Horizontal } \\
\text { COR } \\
\begin{array}{c}\text { Preop./Postop. } \\
\text { (mm) }\end{array} \\
\end{array}$ & comments \\
\hline \multicolumn{9}{|c|}{ Single superior slope augment } \\
\hline 1 & $\mathrm{~F} / 46$ & $\mathrm{~L}$ & $\mathrm{AL}$ & IIIA & $36 / 11$ & $47 / 35$ & $45 / 34$ & \multirow{6}{*}{$\begin{array}{l}\text { Stem not } \\
\text { revised }\end{array}$} \\
\hline 2 & $\mathrm{M} / 56$ & $\mathrm{R}$ & $\mathrm{AL}$ & IIIB & $49 / 13$ & $27 / 33$ & $52 / 35$ & \\
\hline 3 & $\mathrm{M} / 55$ & $\mathrm{R}$ & PJI & IIIA & $44 / 10$ & $37 / 40$ & $40 / 37$ & \\
\hline 4 & $\mathrm{M} / 45$ & $\mathrm{R}$ & $\mathrm{AL}$ & IIIB & $35 / 20$ & $41 / 13$ & $46 / 25$ & \\
\hline 5 & $\mathrm{M} / 67$ & $\mathrm{~L}$ & $\mathrm{AL}$ & IIIB & $49 / 2$ & $28 / 18$ & $37 / 29$ & \\
\hline 6 & $\mathrm{M} / 44$ & $\mathrm{~L}$ & PJI & IIIB & $32 / 9$ & $27 / 28$ & $34 / 33$ & \\
\hline 7 & $\mathrm{M} / 78$ & $\mathrm{~L}$ & $\mathrm{AL}$ & IIIA & $41 / 12$ & $39 / 23$ & $40 / 34$ & \multirow{3}{*}{$\begin{array}{l}\text { Stem not } \\
\text { revised } \\
\text { Stem not } \\
\text { revised }\end{array}$} \\
\hline 8 & $\mathrm{~F} / 73$ & $\mathrm{R}$ & Dislocation & IIIB & $41 / 7$ & $58 / 29$ & $22 / 24$ & \\
\hline 9 & $\mathrm{M} / 68$ & $\mathrm{~L}$ & PJI & IIIA & $41 / 5$ & $34 / 27$ & $52 / 46$ & \\
\hline 10 & $\mathrm{M} / 57$ & $\mathrm{~L}$ & $\mathrm{AL}$ & IIIA & $46 / 11$ & $50 / 25$ & $39 / 34$ & \multirow{5}{*}{$\begin{array}{c}\text { PJI } \\
\text { complication }\end{array}$} \\
\hline 11 & $\mathrm{~F} / 60$ & $\mathrm{~L}$ & $\mathrm{AL}$ & IIIA & $30 / 8$ & $43 / 23$ & $39 / 36$ & \\
\hline 12 & $\mathrm{~F} / 45$ & $\mathrm{~L}$ & $\mathrm{AL}$ & IIIB & $36 / 11$ & $32 / 17$ & $42 / 30$ & \\
\hline 13 & $\mathrm{~F} / 40$ & $\mathrm{R}$ & $\mathrm{AL}$ & IIIA & $32 / 11$ & $28 / 16$ & $36 / 31$ & \\
\hline 14 & $\mathrm{M} / 75$ & $\mathrm{R}$ & $\mathrm{AL}$ & IIIA & $33 / 3$ & $58 / 21$ & $61 / 37$ & \\
\hline \multicolumn{9}{|c|}{ Stacked superior slope augments } \\
\hline 15 & $\mathrm{~F} / 58$ & $\mathrm{~L}$ & Dislocation & IIIB & $40 / 18$ & $58 / 26$ & $30 / 36$ & \multirow{6}{*}{$\mathrm{PD}$} \\
\hline 16 & $\mathrm{M} / 44$ & $\mathrm{~L}$ & Dislocation & IIIB & $41 / 14$ & $78 / 15$ & $47 / 25$ & \\
\hline 17 & $\mathrm{~F} / 52$ & $\mathrm{~L}$ & $\mathrm{AL}$ & IIIB & $40 / 16$ & $32 / 11$ & $31 / 20$ & \\
\hline 18 & $\mathrm{M} / 38$ & $\mathrm{R}$ & PJI & IIIB & $28 / 15$ & $39 / 33$ & $48 / 43$ & \\
\hline 19 & $\mathrm{~F} / 62$ & $\mathrm{~L}$ & $\mathrm{AL}$ & IIIB & $40 / 22$ & $30 / 27$ & $28 / 32$ & \\
\hline 20 & $\mathrm{~F} / 55$ & $\mathrm{~L}$ & Osteolysis & IIIA & $45 / 6$ & $37 / 40$ & $40 / 37$ & \\
\hline
\end{tabular}

COR = Center of Rotation; HHS = Harris Hip Score; Preop. = Preoperatively; Postop. = Postoperatively; $\mathrm{AL}=$ aseptic loosening; PJI= Periprosthetic joint infection; PD = Pelvic Discontinuity

Table. 3 Comparison of preoperative and postoperative clinical and radiological results

\begin{tabular}{lcccc} 
HHS Score & & Preoperative & Postoperative & P \\
& HHS Pain & $3.2 \pm 5.7$ & $40.8 \pm 8.3$ & $\square 0.001$ \\
& HHS Function & $13.4 \pm 10.6$ & $34.2 \pm 15.3$ & $\square 0.001$ \\
& HHS Deformity & $0.5 \pm 1.0$ & $3.3 \pm 3.2$ & $\square 0.001$ \\
WOMAC Score & HHS ROM & $3.3 \pm 3.9$ & $3.7 \pm 1.9$ & 0.605 \\
& Total HHS score & $20.3 \pm 12.6$ & $81.0 \pm 21.7$ & $\square 0.001$ \\
& & & \\
& WOMAC Pain & $8.5 \pm 9.2$ & $1.2 \pm 4.2$ & $\square 0.001$ \\
& WOMAC Stiffness & $2.4 \pm 4$ & $0.2 \pm 0.9$ & $\square 0.001$ \\
& WOMAC Function & $39.4 \pm 31.4$ & $14.6 \pm 16.7$ & $\square 0.001$ \\
Horizontal location of COR from IT line (mm) & Total WOMAC score & $50.3 \pm 38.8$ & $16.0 \pm 19.1$ & $\square 0.001$ \\
Vertical location of COR from IT line (mm) & & $40.3 \pm 22.3$ & $31.5 \pm 12.5$ & $<0.001$ \\
Horizontal deviation from anatomical COR (mm) & & $44.2 \pm 30.4$ & $23.1 \pm 18.8$ & 0.016 \\
Vertical deviation from anatomical COR (mm) & & $28.2 \pm 29.4$ & $5.6 \pm 14.5$ & 0.015 \\
\hline
\end{tabular}

HHS = Harris Hip Score; ROM = Range of Motion; WOMAC = Western Ontario and McMaster Universities Osteoarthritis Index; COR = Center of Rotation; IT line = Inter-Teardrop line; $p$-value $<0.05$ was considered to be statistically significant. 
Table 4. Comparison of preoperative and intraoperative factors between the extracavitary and intracavitary iliac extended fixation.

Extracavitary group

Intracavitary group

$\mathrm{p}$

Left side

$50.0 \%$

$60.0 \%$

0.718

Female gender

$58.3 \%$

$40.0 \%$

0.467

Paprosky classification 3B

$66.7 \%$

$55.0 \%$

0.713

Preoperative HHS Score

$\begin{array}{rccc}\text { HHS Pain } & 2.8 \pm 3.3 & 3.4 \pm 6.6 & 0.624 \\ \text { HHS Function } & 15.2 \pm 8.8 & 12.4 \pm 10.9 & 0.155 \\ \text { HHS Deformity } & 0.3 \pm 1.0 & 0.6 \pm 1.0 & 0.248 \\ \text { HHS ROM } & 1.9 \pm 6.1 & 4.1 \pm 8.1 & 0.125 \\ \text { Total HHS score } & 20.3 \pm 11.2 & 20.4 \pm 13.5 & 0.950\end{array}$

Preoperative WOMAC Score

\begin{tabular}{|c|c|c|c|}
\hline WOMAC Pain & $9.6 \pm 9.7$ & $7.5 \pm 9.7$ & 0.247 \\
\hline WOMAC Stiffness & $2.4 \pm 4.8$ & $2.0 \pm 3.6$ & 0.589 \\
\hline WOMAC Function & $41.8 \pm 30.8$ & $36.7 \pm 34.3$ & 0.414 \\
\hline Total WOMAC score & $53.8 \pm 37.6$ & $46.1 \pm 41.7$ & 0.316 \\
\hline Horizontal location of COR from IT line (mm) & $42.5 \pm 30.2$ & $39.3 \pm 18.4$ & 0.497 \\
\hline Vertical location of COR from IT line (mm) & $56.1 \pm 35.1$ & $38.5 \pm 21.6$ & 0.003 \\
\hline Horizontal deviation from anatomical COR (mm) & $10.8 \pm 36.7$ & $4.6 \pm 21.4$ & 0.248 \\
\hline Vertical deviation from anatomical COR (mm) & $35.8 \pm 40.6$ & $22.9 \pm 18.3$ & 0.021 \\
\hline Proportion of ETO & $16.7 \%$ & $20.0 \%$ & 1.000 \\
\hline Cup diameter (mm) & $55.3 \pm 13.3$ & $57.4 \pm 8.4$ & 0.299 \\
\hline Number of augment used & $2.3 \pm 1.9$ & $1.7 \pm 1.7$ & 0.066 \\
\hline Number of screws for augment fixation & $4.3 \pm 2.8$ & $2.6 \pm 2.5$ & 0.002 \\
\hline Number of screws for cup fixation & $3.2 \pm 1.1$ & $2.9 \pm 2.0$ & 0.415 \\
\hline Total number of screws & $7.4 \pm 2.3$ & $5.5 \pm 3.6$ & 0.003 \\
\hline
\end{tabular}

HHS = Harris Hip Score; ROM = Range of Motion; WOMAC = Western Ontario and McMaster Universities Osteoarthritis Index; COR = Center of Rotation; IT line = Inter-Teardrop line; ETO = Extended Trochanteric Osteotomy; p-value $<0.05$ was considered to be statistically significant. 
Table 4. Comparison of postoperative factors between the extracavitary and intracavitary iliac extended fixation.

\begin{tabular}{|c|c|c|c|}
\hline Radiographic abduction of $\operatorname{cup}\left({ }^{\circ}\right)$ & $40.1 \pm 14.4$ & $37.9 \pm 12.5$ & 0.370 \\
\hline Radiographic anteversion of cup $\left(^{\circ}\right)$ & $13.3 \pm 8.6$ & $11.5 \pm 10.3$ & 0.328 \\
\hline Horizontal location of COR from IT line (mm) & $29.4 \pm 13.7$ & $32.6 \pm 11.9$ & 0.219 \\
\hline Vertical location of COR from IT line (mm) & $20.5 \pm 23.0$ & $23.3 \pm 16.9$ & 0.466 \\
\hline Horizontal deviation from anatomical COR (mm) & $3.5 \pm 13.7$ & $6.3 \pm 14.3$ & 0.295 \\
\hline Vertical deviation from anatomical COR (mm) & $1.3 \pm 13.7$ & $-2.4 \pm 20.4$ & 0.292 \\
\hline \multicolumn{4}{|l|}{ Osteointegration } \\
\hline Zone $1 \mathrm{~A}$ & $91.7 \%$ & $50.0 \%$ & 0.023 \\
\hline Zone 1B & $83.3 \%$ & $95.0 \%$ & 0.540 \\
\hline Zone 2 & $91.7 \%$ & $95.0 \%$ & 1.000 \\
\hline Zone 3 & $100.0 \%$ & $100.0 \%$ & 1.000 \\
\hline \multicolumn{4}{|l|}{ RLL } \\
\hline Zone $1 \mathrm{~A}$ & $16.7 \%$ & $50.0 \%$ & 0.075 \\
\hline Zone 1B & $0.0 \%$ & $0.0 \%$ & 1.000 \\
\hline Zone 2 & $8.3 \%$ & $0.0 \%$ & 0.375 \\
\hline Zone 3 & $0.0 \%$ & $0.0 \%$ & 1.000 \\
\hline Screw-IT angle $\left({ }^{\circ}\right)$ & $4.6 \pm 25.7^{\circ}$ & $41.9 \pm 37.8^{\circ}$ & $<0.001$ \\
\hline Satisfaction rate & $91.7 \%$ & $95.0 \%$ & 1.000 \\
\hline \multicolumn{4}{|l|}{ Postoperative HHS Score } \\
\hline HHS Pain & $40.3 \pm 10.1$ & $41.0 \pm 8.3$ & 0.694 \\
\hline HHS Function & $33.8 \pm 13.8$ & $34.5 \pm 16.3$ & 0.809 \\
\hline HHS Deformity & $3.7 \pm 2.3$ & $3.0 \pm 3.5$ & 0.256 \\
\hline HHS ROM & $3.7 \pm 1.9$ & $3.7 \pm 2.0$ & 0.965 \\
\hline Total HHS score & $80.8 \pm 19.0$ & $81.2 \pm 24.7$ & 0.926 \\
\hline \multicolumn{4}{|l|}{ Postoperative WOMAC Score } \\
\hline WOMAC Pain & $1.4 \pm 4.7$ & $1.3 \pm 4.5$ & 0.892 \\
\hline WOMAC Stiffness & $0.0 \pm 0.0$ & $0.4 \pm 1.0$ & 0.120 \\
\hline WOMAC Function & $16.3 \pm 17.4$ & $14.1 \pm 18.0$ & 0.496 \\
\hline Total WOMAC score & $17.8 \pm 21.1$ & $15.7 \pm 20.5$ & 0.600 \\
\hline
\end{tabular}

HHS $=$ Harris Hip Score; ROM = Range of Motion; WOMAC = Western Ontario and McMaster Universities Osteoarthritis Index; $\mathrm{COR}=$ Center of Rotation; IT line $=$ Inter-Teardrop line; RLL $=$ Radiolucent Line; $\mathrm{p}$-value $<0.05$ was considered to be statistically significant.

\section{Figures}



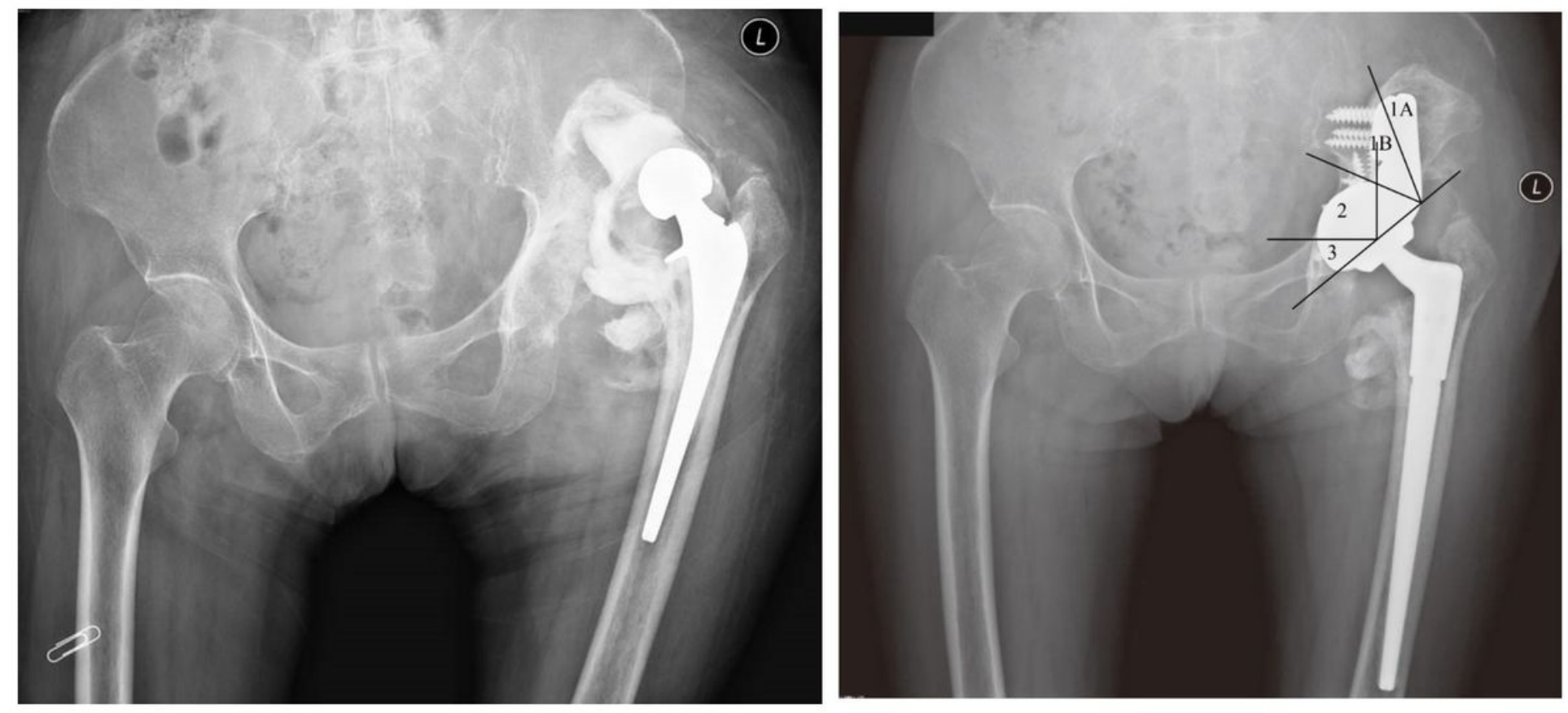

\section{Figure 1}

A case of extracavitary iliac extended fixation. Preoperative radiograph (left panel) demonstrates loosening and migration of a cemented acetabular cup, pelvic discontinuity, and severe non-cavitary superior bone defect ( $1 \mathrm{~A})$, which was reconstructed with a buttress augment and a shim augment combined with a hemispherical cementless cup (1B). The Delee-Charnley zone 1 was further divided into the lateral zone 1A and medial zone 1B by the line connecting the lateral junction of buttress-cup interface and the superior corner of the buttress augment.

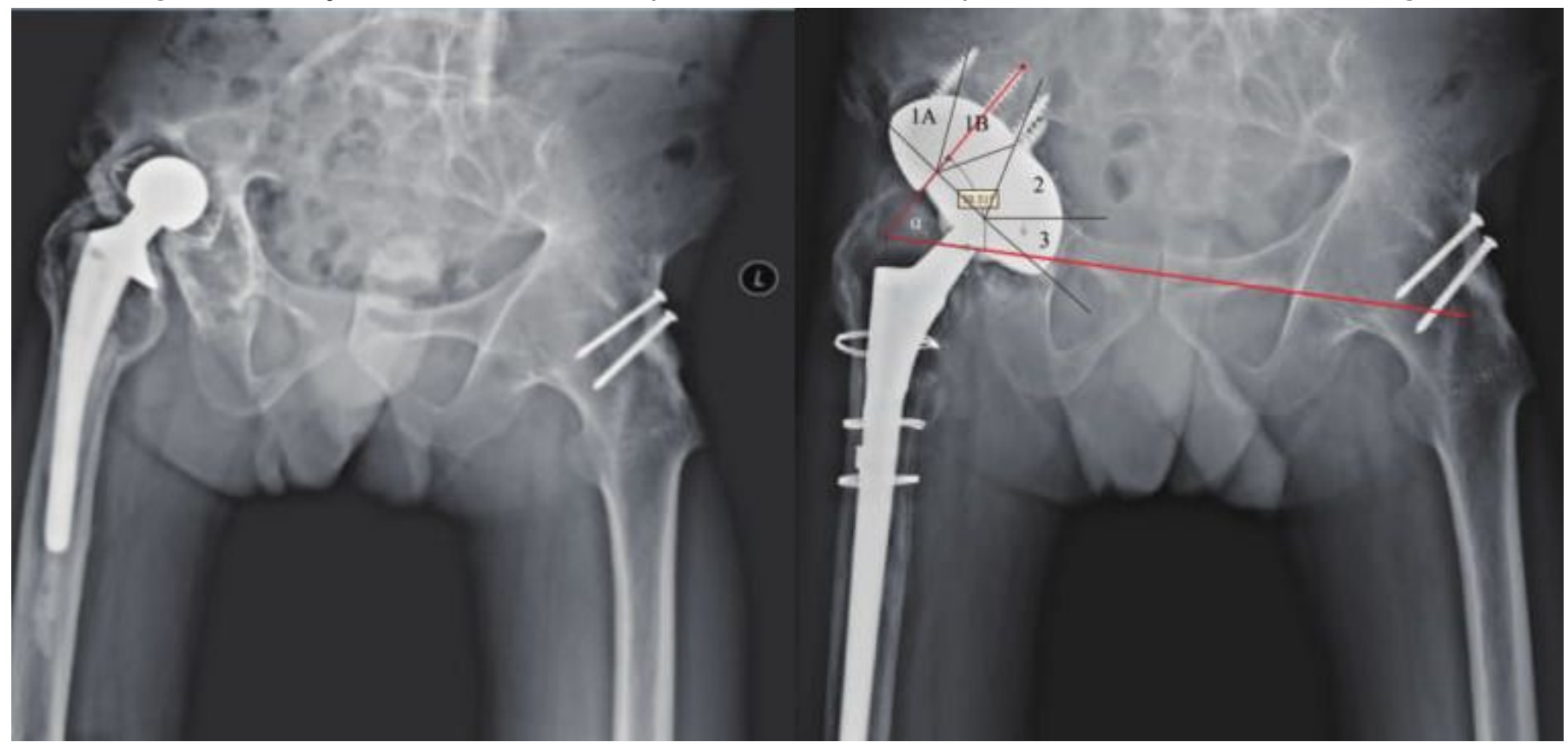

\section{Figure 2}

A case of intracavitary iliac extended fixation with a single slope augment. Preoperative radiograph (2A) demonstrates cranial migration and loosening of a cemented cup and severe intracavitary bone defect in the ilium, which was reconstructed with a single superior slope augment and a hemispherical cementless cup (2B). The Delee- 
Charnley zone 1 was bisected from the center of the arc of the slope augment into zone $1 \mathrm{~A}$ and $1 \mathrm{~B}$. Orientation of screws fixing the augments was measured in reference to the inter-teardrop line.

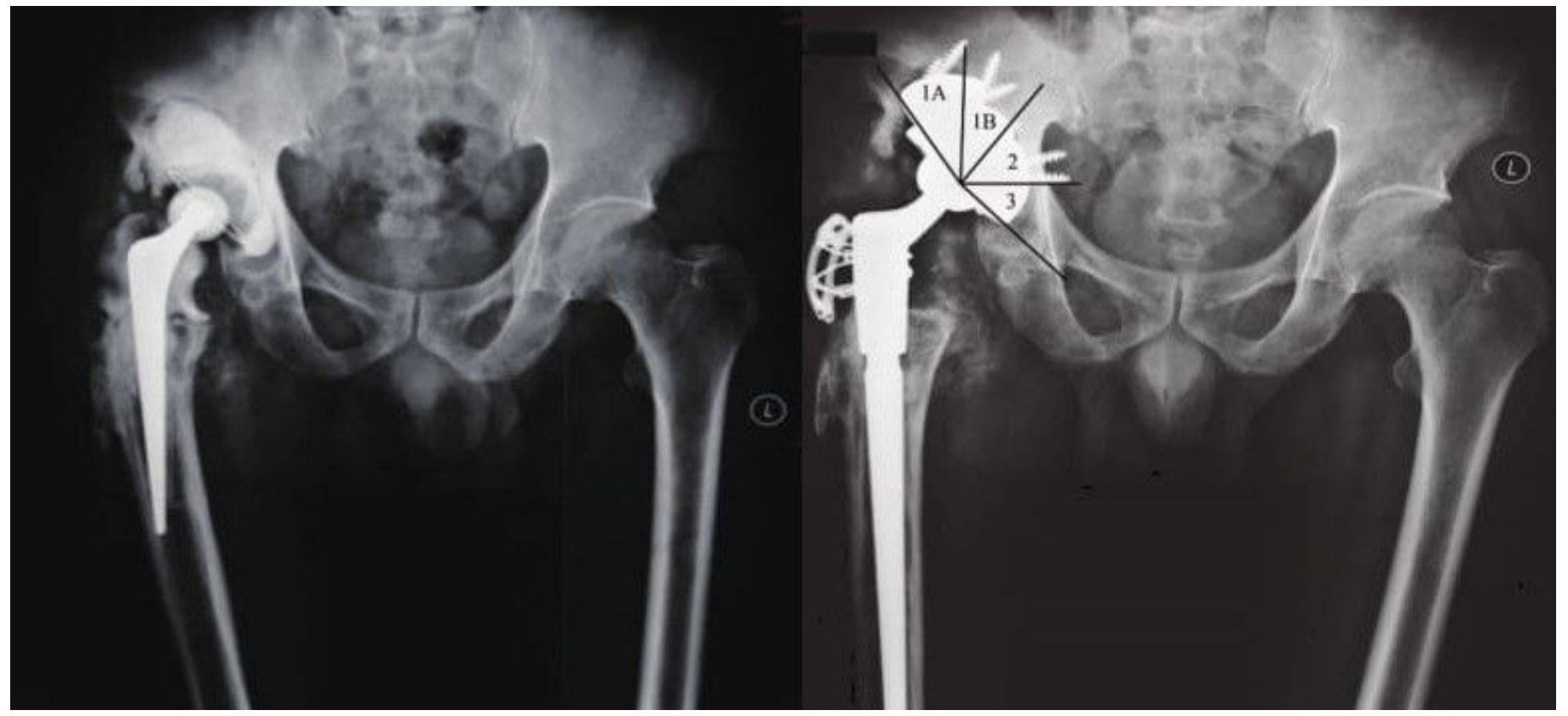

\section{Figure 3}

A case of intracavitary iliac extended fixation with stacked augments. Preoperative radiograph (3A) reveals severe osteolysis and a cavitary bone defect in the ilium, which was reconstructed with two stacked augments combined with a hemispherical cementless cup, when a single augment was unable to fully fill the defect (3B). The DeleeCharnley zone 1 around the stacked augments was further bisected from the center of rotation into zone 1A and 1B. 